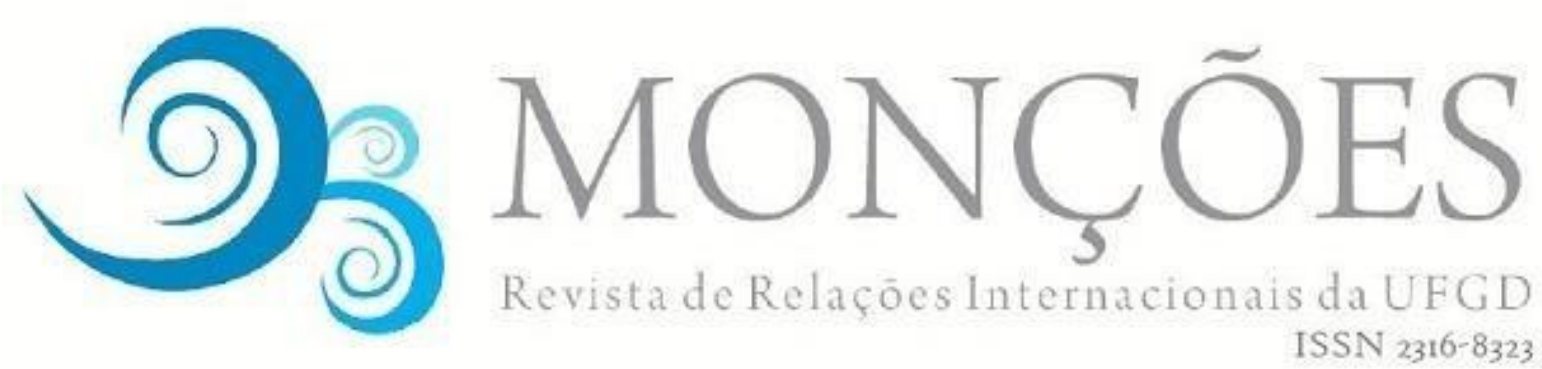

\title{
RELAÇÕES INTERNACIONAIS, TEORIAS FEMINISTAS E PRODUÇÃO DE CONHECIMENTO: UM BALANÇO DAS CONTRIBUIÇÕES RECENTES
}

\author{
RAISSA WIHBY VENTURA \\ Doutoranda em Ciência Política pela Universidade de São Paulo (DCP-USP). Participa \\ do Grupo de Pesquisa em Teoria Política (Getepol) e do Núcleo de pesquisa em Relações \\ Internacionais (Nupri). Atualmente é pesquisadora visitante do Instituto de Filosofia no \\ Consejo Superior de Investigaciones Científicas (Madrid). Este trabalho recebeu \\ financiamento do CNPq (163953/2014-7) e da Capes-PDSE (88881.131577/2016-01).
}

RAQUEL KRITSCH

Doutora pela Universidade de São Paulo e professora-pesquisadora junto ao Departamento e Programa de Mestrado em Ciências Sociais da Universidade Estadual de Londrina. Investigação vinculada ao projeto de pesquisa intitulado "Para além da constelação nacional? Disputas em torno da cidadania, do cosmopolitismo e dos direitos humanos na teoria política contemporânea II", financiado pelo CNPq (308350/2014-6) e apoiado pela

UEL.

RESUMO: O objetivo geral deste artigo é mostrar como diferentes perspectivas epistemológicas formuladas pelas teorias feministas no último quartel do século $X X$ foram apropriadas pelo campo das Relações Internacionais e geraram posições distintas para e sobre a produção de conhecimento na área. Para tanto, o texto foi estruturado em três seções. A primeira será dedicada a uma discussão sobre epistemologia feminista. Na segunda seção, serão apresentados e discutidos os diferentes traços que compõem o desenho conceitual que delineia o encontro entre epistemologias feministas e RI. Por fim, na terceira seção, pretendemos defender o argumento de acordo com o qual, não obstante suas diferenças, as perspectivas sobre a produção de conhecimento feminista em RI não são necessariamente excludentes. Os feminismos e suas agendas de pesquisa partem da necessidade de se oferecer alternativas a um modo dominante de produção do conhecimento em que as relações de gênero bem como as mulheres, suas histórias, seus lugares de enunciação e pontos de vista são construídos e reproduzidos na e pela disciplina dentro de um quadro que exclui sistematicamente as mulheres e o feminino das atividades, do campo e da produção de conhecimento disciplinar.

PALAVRAS-CHAVE: Feminismos; Relações Internacionais; Epistemologias. 


\title{
INTERNATIONAL RELATIONS, FEMINIST THEORIES AND KNOWLEDGE PRODUCTION: A REVIEW OF THE RECENT CONTRIBUTIONS
}

\begin{abstract}
The main goal of this article is to show how different epistemological perspectives formulated by feminist theories in the last quarter of the twentieth century were appropriated by the field of International Relations and have originated distinct positions for and about the production of knowledge in the field. To reach this aim, the text was structured in three sections. The first section will focus on feminist epistemology. In the second section, the lines that compose the conceptual draw delineating the encounter between feminist epistemologies and IR will be presented and discussed. Finally, in the third section, we intend to defend the argument according to which, despite their differences, the perspectives on the production of feminist knowledge of the IR are not necessarily excluding. Feminisms and their research agendas depart from the need to offer an alternative to a dominant mode of knowledge production in which the gender relations as well the women, their histories, their places of enunciation and points of view are constructed and reproduced by the discipline within a framework that systematically exclude women and the feminine from the discipline's activities, field and production of knowledge.
\end{abstract}

KEYWORDS: Feminisms; International Relations; Epistemologies.

\section{À guisa de Introdução'}

As questões que poderiam ser formuladas a partir do encontro entre os diversos feminismos e as Relações Internacionais (RI) são tanto intrigantes quanto variadas. Reconhecer que o gênero pode ser uma categoria ou unidade de análise importante e/ou que o ponto de vista das mulheres tem alguma especificidade para 0 campo das RI cria um leque de possibilidades que merecem atenção especial. Deste modo, além de responder à pergunta sobre a relevância dos feminismos para as RI, pretendemos neste artigo apresentar diferentes arranjos, traços e pontos de encontro possíveis entre esses dois campos a partir de uma discussão sobre epistemologias feministas. Ao final espera-se que a(o) leitor(a) compreenda que a produção de conhecimento feminista nas/das $\mathrm{RI}$ aceitam múltiplas combinações possíveis entre objeto, problema de pesquisa, teoria, método e metodologia².

\footnotetext{
${ }_{1}^{1}$ Agradecemos às(aos) pareceristas anônim(o)as desta revista a leitura cuidadosa e os comentários detalhados. Todas as afirmações deste trabalho, no entanto, são de nossa inteira responsabilidade.

2 É importante estabelecermos um acordo semântico para os termos método e metodologia. Método será aqui definido como uma técnica, ou conjunto de técnicas, usadas para captar e analisar
} 
Os níveis em que são desenvolvidas as pesquisas que se reconhecem como feministas no campo das RI variam consideravelmente entre si. Uma pesquisa pode, por exemplo, questionar a estrutura interna das explicações tradicionais de um campo mobilizando conceitos como gênero e sexo sem, contudo, problematizar as metodologias que são constitutivas do cânone das RI. Ou então, é possível questionar o tipo de objeto que as teorias tradicionais das $\mathrm{Rl}^{3}$ reconhecem como constitutivos e próprios do campo a partir do ponto de vista de agentes - as mulheres, por exemplo - que são reiteradamente excluída(o)s por essas divisões disciplinares, sem, todavia, produzir explicações diferentes sobre o fenômeno em questão. Uma terceira combinação possível é aquela posição que questiona a estrutura interna das teorias, suas análises e explicações, suspende a validade das divisões disciplinares que definem qual objeto é legítimo para o campo e produz resultados diferentes daqueles definidos como tradicionais.

Identificar essas diferentes combinações (ou níveis) é fundamental para que se entenda de que modo os feminismos nas $\mathrm{Rl}$ carregam a potencialidade de produzir conhecimento e propor desenhos de pesquisa variados para o campo. As escolhas sobre qual será o objeto ou o sujeito da pesquisa, as definições sobre como este sujeito será tratado - ou apreendido, se for entendido como objeto teoricamente e as escolhas a respeito de como a pesquisa deverá proceder incluindo qual técnica a ser empregada para a análise das evidências, nos casos em

evidências. Por metodologia entende-se a definição de como uma pesquisa deve proceder, isto é, diz respeito às teorias e análises dos procedimentos de investigação (HARDING, 1987, p.2-3).

${ }^{3}$ É pouco contestada a afirmação de que com o fim da Guerra Fria e com aumento das relações de interdependência entre os Estados, resultado do que se convencionou chamar de processo de globalização, as teorias das RI passaram a enfrentar demandas por mudanças em sua estrutura e conteúdo. O realismo deixou de ser concebido como fonte inesgotável de explicação para os acontecimentos que envolveriam a guerra e a segurança, cedendo cada vez mais espaço para explicações concorrentes. Neste contexto, análises sobre política econômica internacional, desenvolvimento socioeconômico, direitos humanos, atores não-estatais e a sociedade civil identificadas como liberais - foram ganhando espaço e reconhecimento no campo. Realistas e liberais serão tratados como as correntes representantes do que será chamado nas próximas páginas de teorias tradicionais das $R I$ (cf. RUIZ, 2005). Um outro modo de definir este conjunto de teorias é a partir de sua aproximação com o que Tickner (cf. 2011: n/p. 5) denominou "metodologia das ciências sociais". Ainda que esta última proposta de definição pareça mais adequada é preciso cautela, pois as características que Tickner aponta como constitutivas da metodologia das ciências sociais poderiam ser facilmente confundidas com perspectivas feministas empiristas/racionalistas, razão pela qual será evitada aqui. 
que este tipo de terminologia é cabível - são passos importantes para que se examine que tipo de conhecimento está sendo produzido a partir destes pontos de encontro entre teorias feministas e RI.

Definir e explorar a complexidade destas escolhas e as consequências para a consolidação e produção de conhecimento atento ao gênero e ao feminismo nas RI é o objetivo deste artigo. A proposta, portanto, não é discutir ou apresentar detalhadamente cada uma destas possibilidades e encaixes. A ideia aqui é mais geral: pretende-se apresentar de que modo diferentes pontos de encontro entre esses dois campos geram perspectivas teóricas distintas, ainda que não necessariamente excludentes, para a produção de conhecimento ${ }^{4}$. Em forma de pergunta, pretende-se aqui buscar respostas para a seguinte pergunta: $O$ conhecimento produzido a partir dos pontos de encontro entre o campo das $R I$ e o dos feminismos carrega potencialidades úteis à produção de explicações, à formulação de teorias e à elaboração de questões/problemas e métodos de pesquisa?

Para responder a esta questão, as páginas que seguem foram organizadas em três seções. A primeira seção será dedica a uma breve discussão sobre epistemologia feminista. Na segunda seção, as partes e linhas que compõem o encontro entre epistemologias feministas e RI serão apresentadas e discutidas, a fim de que fique evidente como cada ponto de intersecção entre os dois campos carrega potencialidades e traços específicos que devem ser identificados e entendidos. Por fim, na terceira seção, pretende-se defender o argumento de acordo com o qual, não obstante as diferenças, perspectivas sobre a produção de conhecimento feminista nas RI não são necessariamente excludentes. E mais: se bem compreendidas, pode-se afirmar certa complementaridade entre elas no que respeita ao alcance de um objetivo comum, qual seja: combater um tipo de silêncio violento que se perpetua no mundo da produção de conhecimento.

\footnotetext{
${ }^{4}$ Poderia ser dito, ainda, que há um encontro anterior entre as teorias feministas e a epistemologia a ser investigado, e não pressuposto como está se fazendo aqui. É fato que o encontro entre as teorias feministas e a filosofia da ciência e a epistemologia têm uma história específica e bastante complexa (cf. GRASSWICK, 2011). Porém, nos limites deste artigo, não será possível apresentar nada além de uma definição sobre o que se está pressupondo como epistemologia feminista. Portanto, se a leitora ou o leitor estiver esperando um texto filosófico sobre as contribuições e limites dos feminismos para a epistemologia ou filosofia da ciência, infelizmente, frustrar-se-á ao ler este texto.
} 


\section{Epistemologia Feminista: definições gerais}

Se é possível sustentar que as teorias feministas oferecem uma contribuição própria para a epistemologia, o que significa, então, afirmar que existe uma epistemologia feminista?

A epistemologia feminista, em linhas gerais, tem como objeto o(s) modo(s) em que o gênero influencia a nossa concepção compartilhada de conhecimento, as práticas de pesquisa e justificação que podem ser consideradas legítimas. Nesse sentido, ao se pôr em relevo a estrutura de gênero e/ou o papel do gênero na produção do conhecimento (e, mais especificamente, da ciência), identifica-se de que maneira concepções e práticas dominantes relativas à atribuição, aquisição e justificação do conhecimento resultam na condenação sistemática das mulheres - e outros grupos sociais que ocupam um lugar de subordinação - a uma posição de desvantagem e/ou de subordinação (cf. ANDERSON, 2000; 1995).

Condenar mulheres a posições desvantajosas implica a exclusão das mulheres das investigações; negar a elas a posição de autoridade epistêmica; denigrir aquilo que é identificado com um estilo cognitivo e com modos de conhecimento "femininos"; a produção de teorias sobre as mulheres que as representa como inferiores, desviantes (ou, alternativamente, como significativas somente na medida em que servem aos interesses dos homens); a produção de teorias sociais ou explicações sobre determinados fenômenos que invisibilizam as mulheres ou o "feminino", suas atividades e interesses, entre outras consequências nefastas à(s) causa(s) feminista(s). (ANDERSON, 2000)

Identificados os problemas, ainda que de modo esquemático, pode-se afirmar que dois objetivos básicos são compartilhados por uma epistemologia feminista: legitimar uma ciência que (i) compartilhe objetivos e fins feministas e (ii) subscreva a crítica feminista ao sexismo e à ciência androcêntrica. Ainda que se possa afirmar que tais objetivos pareçam, em um primeiro momento, bastante limitados ao campo da ciência, uma interpretação mais fiel aos propósitos desta abordagem seria aquela que compreende terem como foco tais objetivos a transformação do pano de fundo das condições sociais em que a ciência é 
produzida. Uma jornada eminentemente política, mas que se justifica também a partir de valores epistêmicos - tais como a razão e a adequação empírica, valores aos quais, sabemos, a ciência se declara leal (ANDERSON,1995, p.56).

Ainda que útil, essa definição não nos permite, no entanto, responder à questão sobre o que significa afirmar que uma pesquisa parte ou ancora-se em uma epistemologia feminista. O comprometimento com uma epistemologia feminista pode significar diferentes coisas, dentre elas: (i) o engajamento com o ponto de vista de agentes epistêmicos, concebendo-a(o)s em suas particularidades e contextos como agentes sociais politicamente situados; (ii) destacar as particularidades dos contextos a partir dos quais questões epistêmicas surgem e devem ser respondidas, sempre com o compromisso de evidenciar estruturas sociais e políticas que normalmente estão, de algum modo, camufladas; (iii) por fim, pode significar contribuir com demandas políticas feministas, provendo análises tanto descritivas dos aspectos da opressão e da dominação de gênero - quanto normativas, oferecendo caminhos possíveis para mudanças no sentido da eliminação destas relações de dominação e opressão (DAUKAS, 2011, p.48).

Compreender a extensão de cada um desses objetivos e significados teóricos e epistemológicos nos leva a reconhecer que as pretensões das teorias e modelos que partem desse lugar-comum não se encerram na projeção de caminhos possíveis para promoção de mudanças sociais relativas às estruturas de dominação e opressão de gênero. Tal observação é relevante na medida em que o foco da discussão que se segue não consiste em analisar ou identificar projetos normativos feministas, e sim limita-se a desvendar de que modo as teorias feministas podem também ser lidas como uma proposta de transformação cognitiva que também abrange as RI. Assim, uma pesquisa nas RI que partilha uma perspectiva epistemológica feminista formula respostas próprias para problemas centrais que aquelas e aqueles que produzem algum tipo de conhecimento precisam enfrentar, tais como: $O$ que deve ser objeto de uma pesquisa? Sobre o que e como podemos 
produzir conhecimento? Que técnicas devem ser adotadas para que este conhecimento possa ser produzido ?5 (cf. HANSEN, 2010)

\section{Epistemologias em ação nas RI: feminismo empirista/racionalista, ponto de vista feminista e feminismo pós-moderno}

A história das intervenções feministas em diferentes disciplinas costuma seguir um certo padrão. O início é geralmente marcado pelas críticas aos métodos, pressupostos e teorias aceitas como tradicionais pelo campo. Com o estabelecimento de suas produções, uma outra fase inicia-se: projetos mais propositivos começam a ser idealizados e colocados em prática (cf. ANDERSON, 2000). A suposição aqui é, seguindo Anderson, a de que os feminismos nas RI já avançaram no sentido de não poderem mais ser reduzidos à formulação de críticas ou respostas para aquilo que está posto pelas $\mathrm{RI}$ tradicionais. $\mathrm{E}$ mais, com Cyntia Weber (2010, p.104), leva-se a sério a ideia de que para entender a dimensão e o impacto das teorias feministas nas RI é preciso concentrar-se nas próprias feministas e suas produções.

Isso quer dizer que as próximas páginas são uma tentativa de mapear projetos feministas que apresentam certa coerência interna e não se encerram nas críticas à produção teórica tradicional das RI. Sendo assim, será parte das tarefas a serem cumpridas evidenciar de que modo as decisões sobre o que é considerado relevante para ser estudado e como isto deve ser estudado/pesquisado dependem

\footnotetext{
5 Já foi dito que o objetivo é o de apresentar uma certa discussão sobre as potencialidades geradas pelos pontos de encontro entre epistemologias feministas e a produção de conhecimento nas RI. Relacionada a este ponto, mas que mereceria uma atenção especial, está uma discussão sobre se é possível afirmar a existência de metodologias feministas e, caso existam, definir quais seriam. Para esta discussão, que não está restrita às RI, cf. Maynard e Purvis (1994); DeVault (1999); D. Smith (1999); Harding (1987). Para uma crítica feminista pós-colonial às metodologias tradicionais, cf. Basu (1995); L.T. Smith (1999). Para uma apresentação sobre as diversas metodologias usadas em pesquisas feministas, cf. Klein (1983); Cook e Fonow (1986); Nielsen (1990); Reinharz (1992); Gluck e Patai (1991). Ainda sobre este ponto, como deverá ficar mais evidente na segunda seção deste texto, seguindo Laurel Weldon (2006), também neste artigo metodologias empregadas por feministas serão entendidas como "epistemologias em ação". Ter como foco as discussões metodológicas sem antes olhar para as definições epistemológicas parece ser um erro que se pretende evitar ao longo destas páginas.
} 
de um conjunto de escolhas que precisam ser feitas e justificadas pela(o) pesquisadora $(r)^{6 .}$

Dito isso, com o intuito de colocar em evidência uma espécie de fio-condutor que formaria agendas de pesquisa feministas das RI, as próximas subseções deverão responder às seguintes perguntas:

(i) quais são os problemas de pesquisa (ou questões) a serem mobilizadas como modelos da perspectiva em questão;

(ii) qual conceito de Estado (unidade de análise) é empregado;

(iii) que conceito de gênero (unidade de análise) é usado;

(iv) qual(is) são as ferramentas ou técnicas de pesquisa comumente utilizadas;

(v) quais são as características mais gerais desta perspectiva epistemológica que não se encerram no campo das RI;

(v) pesquisas que exemplificam a perspectiva em questão.

Seguindo Christine Sylvester (2004, cap.8), Lena Hansen (2010, p.17-27), Robert Keohane (1989) e Cynthia Weber (1994) $)^{7}$, propomos aplicar a divisão formulada por Sandra Harding (1986) para as produções feministas das $\mathrm{RI}^{8}$. Assim,

\footnotetext{
${ }^{6}$ As definições sobre o método e suas ferramentas, sobre qual deve ser o objeto de pesquisa, sobre como podemos produzir conhecimento e sobre o que devemos produzir conhecimento, sobre que técnicas devem ser usadas para captar e avaliar as evidências em questão, etc., podem ser mais ou menos discutidas em cada trabalho. No entanto, ainda que as respostas não necessariamente constituem seu objetivo primeiro, disso não se deriva que tais decisões não precisam ser tomadas. Isso porque, para usar a analogia proposta por Hansen (2010, p.17), cada uma dessas decisões garantirá o bom funcionamento da engrenagem analítica da pesquisa.

${ }^{7} \mathrm{O}$ que não quer dizer que a(o)s autor(e)as façam os mesmos usos da divisão proposta por Harding, afirmação válida especialmente para Keohane e Weber.

8 Vale notar que quando Harding (1986) propôs uma classificação entre epistemologias feministas, seu objetivo era o de marcar a diferença entre cada uma das vertentes - feminismo empirista, ponto de vista feminista e pós-moderno. Entretanto, os avanços dos últimos anos questionam cada vez mais a rigidez desta divisão - o que, cumpre lembrar, Harding já havia assinalado (cf. HARDING, 1991; 1998). Atentar para essa informação não invalida, em nenhum sentido, o exercício de analisarmos as perspectivas e como elas são mobilizadas nas RI, gerando pesquisas e produzindo conhecimentos que guardam diferenças relevantes entre si. No entanto, o alerta é importante no sentido de mostrar que essa divisão cria tipos-ideais que, na prática, podem ter pontos de intersecção.
} 
as próximas seções serão dedicadas à apresentação de três perspectivas feminismo empirista/racionalista ${ }^{9}$, ponto de vista feminista e feminismo pós-moderno -, tendo como foco a produção de conhecimento feminista nas Relações Internacionais. A intenção, ao percorrer este caminho, não é apenas a de trazer para a discussão as possibilidades de pesquisa e seus desenhos específicos para um certo campo do conhecimento. É importante também compreender quais contribuições os feminismos podem trazer para uma disciplina que, se aceitarmos o diagnóstico de Ticker $(1992)^{10}$, é feita por e (re)produz conhecimento por meio de homens e para homens.

\subsection{Feminismo Empirista/Racionalista nas $\mathbf{R I}^{11}$}

O pressuposto básico da perspectiva racionalista ${ }^{12}$ é a afirmação de acordo com a qual o Estado é o ator central na definição das relações internacionais -

\footnotetext{
${ }^{9} \mathrm{O}$ termo racionalista está sendo empregado aqui para designar o empirismo porque, como alerta Hansen (2010, p.19), é o termo comumente empregado nas RI. Confere também as notas de rodapé $n^{\circ} 9$ e 10

${ }^{10}$ Nas palavras da autora: "A política internacional é uma esfera de atividade tão masculinizada que as vozes das mulheres não são consideradas autênticas (...). Os valores e premissas que embasam nosso sistema internacional contemporâneo são intrinsecamente relacionados ao conceito de masculinidade; privilegiar estes valores limitam as opções disponíveis aos Estados e seus policymakers. Todo conhecimento é parcial e é parte da experiência vivida no mundo por aquele(a) que produz esse conhecimento. Na medida em que o conhecimento sobre o comportamento dos Estados no sistema internacional depende de hipóteses que surgem a partir das experiências dos homens, ignora uma parte significativa de experiências humanas que têm o potencial de expandir o leque de opções e que podem abrir caminhos para novas maneiras de se pensar sobre as práticas entre Estados" (TICKNER, 1992, p.4-17).
}

11 O empirismo e o racionalismo podem, de algum modo, ser tratados como um conjunto, especialmente quando se tem em mente a análise kantiana das estruturas transcendentais da razão e da percepção, tal como se pode ler em seu Crítica da Razão Pura (cf. HOFFE, 2003, p.53-61 e seg.). Aqui estão sendo abordados como intercambiáveis seguindo a denominação proposta por Robert Keohane, canônica na área. Para o autor, a perspectiva racionalista nas RI pode ser definida como aquela que propõe formular teorias causais sobre o comportamento dos Estados, das instituições internacionais e dos atores transnacionais (cf. HANSEN, 2010).

12 É importante que não se confunda o sentido que o termo racionalista tem aqui com o racionalismo moderno ou continental, que faz referência aos trabalhos de René Descartes, Baruch Spinoza e/ou Gottfried Leibniz. Sem entrar nos detalhes desta discussão filosófica, vale destacar alguns pontos. Ainda que as diferenças entre cada um destes importantes filósofos não devam ser desprezadas, o que há de comum entre eles e que justifica o epíteto racionalistas é a ideia de que a matemática e a 
entendidas tanto como uma prática quanto como um campo teórico - podendo ser tratado como um agente que age buscando maximizar sua sobrevivência. Tal afirmação não implica a aceitação necessária da tradição realista, o que nos leva a concluir que nem toda perspectiva feminista racionalista/empirista é, necessariamente, realista. É possível partir desta percepção sobre os Estados e se alinhar a um ponto de vista liberal, por exemplo. A tradição dos Estudos sobre Resolução de Conflitos e Estudos sobre a Paz, para lembrar alguns casos, rejeita várias das suposições realistas sobre a natureza do Estado, seu comportamento e sobre a inevitabilidade da guerra, e se encaixa na perspectiva racionalista (cf. HANSEN,2010).

Como estas ideias se relacionam com o gênero? Sabemos que não decorre necessariamente dessa perspectiva sobre o estado e/ou do foco nos temas da guerra e/ou da paz uma teoria feminista ou uma apreensão feminista das relações internacionais. Sendo assim, parte do esforço empreendido por autora(e)s que defendem essa perspectiva é justamente voltado a mostrar em que medida o gênero é uma categoria, ou uma variável, que pode ter impacto significativo no comportamento dos Estados. Ou então, pelo caminho inverso, de que modo a guerra e a política internacional impactam homens e mulheres.

Se o Estado é o ator central na definição das relações internacionais e se o gênero é uma variável ${ }^{13}$ que representa a divisão biológica (e/ou social) ${ }^{14}$ e empírica entre homens e mulheres, então qual tipo de técnica ou conjunto de ferramentas metodológicas deve ser mobilizado?

Não é de causar espanto que, com frequência, as pesquisas que se encaixam neste tipo-ideal adotem modelos quantitativos como parte de sua opção

geometria oferecem modelos apropriados que serviriam de base para a metodologia filosófica. Para esta visão, a razão é a única capaz de oferecer uma fundamentação segura para o conhecimento humano. Feministas que se dedicaram a esse debate formularam duras críticas, em especial, aos trabalhos de Descartes. Uma tentativa de organizar o debate é proposta por Moira Gatens (2000).

${ }^{13}$ Para uma discussão sobre a possibilidade de se usar gênero como uma variável que poderia contribuir para o campo das RI, cf. Jones (1996); Weber (2010; cap.5).

14 Ainda que se possa dizer que a maior parte das pesquisas trata o gênero como uma categoria biológica, esta não é uma decorrência necessária da adoção do empirismo e nem todas as pesquisas que correspondem ao perfil descrito aqui afirmam esta relação. 
relativa ao método. Isso quer dizer que se pretende produzir dados que contemplem um amplo leque de observações testáveis e combináveis de diferentes maneiras inclusive com outros marcadores, tais como, renda, etnicidade, educação, local de residência, filiação política, e assim por diante -, a fim de se encontrar correlações significativas entre as variáveis que compõem a pesquisa. Outra possibilidade bastante comum é a escolha de um caso que é controlado por suas variáveis dependente e independente(s). Os estudos de caso comparados são, do mesmo modo, parte importante das possibilidades de desenho de pesquisa desta perspectiva.

A partir do que foi dito até aqui, podemos formular uma concepção mais geral sobre os usos dos termos empirismo e racionalismo que estão sendo empregados para identificar uma certa mirada entre as teorias feministas nas RI. Empirismo é a visão segundo a qual a experiência provê todas as evidências que podemos ter sobre o mundo, resume Anderson (1995, p.51). Ou então, em um sentido mais modesto, empirismo é a afirmação de acordo com a qual a observação provê a evidência mínima que temos sobre o mundo (cf. LONGINO, 1993a). O feminismo adiciona ao empirismo a ideia de que o conhecimento científico é contextual e, principalmente, situado (INTEMANN, 2010, p.779; HARAWAY, 1988).

Esse empirismo feminista encontra o racionalismo na medida em que se percebe que a concepção tradicional da razão individualista e autossuficiente é, na realidade, androcêntrica, opressiva e atende apenas aos interesses dos homens, devendo, portanto, ser substituída por uma ideia de razão reflexiva e autogovernada (BORDO, 1987; DURAN, 1991). É com essa ideia de razão que poder-se-ia conceber as experiências contextuais particulares.

Outra formulação ainda merece destaque: a pesquisa empírica, que obviamente depende da razão, é uma empreitada social (LONGINO, 1990; NELSON, 1990). Por isso, tudo que conta como uma evidência para um corpo teórico deve se tornar público e, em contexto experimental, replicável por outra(o)s. Pesquisadoras e pesquisadores devem ser capazes de, e até deveriam ser encorajados a, usarem bancos de dados, métodos, ferramentas e arcabouços conceituais desenvolvidos por outra(o)s (ANDERSON, 1995. p.53; COADY, 1992) - 
afirmação que ganha sentido especial para uma perspectiva que reconhece a importância de metodologias quantitativas que dependem da produção e utilização de bancos de dados, estatísticas, ferramentas operacionais e assim por diante.

Se operamos então com tais distinções e juntamos todos estes passos, podemos definir ao menos dois tipos de agenda de pesquisa para as RI (HANSEN, 2010). Primeiro, encontramos as feministas quantitativas, cujas pesquisas estão fortemente conectadas àquelas elaboradas pela tradição dos Estudos Sobre a Paz (Peace Research). Daí surgem as pesquisas que buscam evidências para a relação entre o comportamento dos Estados e gênero. Ou então, a promoção da igualdade entre gêneros internamente e a entrada deste país em guerras (CAPRIOLI, 2000, 2003, 2003a, 2004; CAPRIOLI; BOYER, 2001; REGAN; PASKEVIVIUTE, 2003; MELANDER, 2005). Ainda em busca de relações causais, mas de modo mais indireto, estão os trabalhos que pretendem evidenciar o já bastante conhecido gender-gap no contexto da política externa (TOGEBY, 1994; EICHENBERG, 2003).

Responder à pergunta sobre como normas generificadas afetam diferentes âmbitos da política externa é outro exemplo de problema de pesquisa relevante para o empirismo. Para responder a esta questão, o objeto pode ser, para citar um caso, as organizações internacionais e o modo como operam as evacuações em zonas de guerra (FINNEMORE; SIKKINK, 1998; CARPENTER, 2003). Um outro problema de pesquisa interessante elaborado por essa perspectiva questiona o modo como os direitos humanos são tratados pelas normativas internacionais, no sentido de definir se realmente são sensíveis às experiências das mulheres que são vítimas de formas complexas de dominação e opressão de gênero (CAPRIOLI, 2004).

Contra esta agenda de pesquisa e as opções mais gerais que ancoram tal posição poderia se dizer que, ao utilizarem gênero como uma categoria ou variável empírica, estas pesquisas acabam por biologizar aquilo que é, para usar a definição de Susan Okin, "a institucionalização social das diferenças sexuais” (2008, p.306). Feministas, escreveu Catherine MacKinnon (1987, p.35), possuem este hábito desagradável de contar corpos recusando-se a notar seu gênero. Outra possibilidade de crítica pode ser a de que esse tipo de pesquisa se encaixa perfeitamente naquilo que Tickner (2006) denominou "metodologia das ciências 
sociais"15. Deste modo, por partilharem os pressupostos positivistas fundamentais da metodologia das ciências sociais, essas pesquisas não poderiam ser consideradas feministas, ao menos no sentido empregado pela autora.

Concordando ou não com a fragilidade desta posição, talvez a melhor maneira de compreender as contribuições desta vertente seja reforçando algumas ideias. Primeiro, o trabalho destas feministas pode ser uma evidência importante para a afirmação de acordo com a qual métodos quantitativos e os feminismos não são mutuamente excludentes. É o que argumenta Mary Caprioli (2004, pp.253-254) contra autoras feministas (PETERSON, 1992; SYLVESTER, 1994; KINSELLA, 2003; STREANS, 2003) que não reconhecem como feministas trabalhos empiristas nas RI em virtude do tipo de método empregado em suas pesquisas. Segundo Caprioli, qualificar um trabalho como feminista (ou não) somente a partir da avaliação do seu método é um julgamento frágil e inadequado. Ainda de acordo com a autora, os trabalhos de feministas racionalistas/empiristas podem contribuir para a agenda das demandas feministas - que reivindicam liberdade, igualdade e autogoverno (DIETZ, 1985) -, além de poderem fomentar o combate a formas de dominação hierárquicas, uso da força militar, dentre outras formas de exploração e dominação (BROCKUTNE,1985).

Segundo ponto importante: essa não é uma perspectiva que pretende oferecer uma alternativa ao modo tradicional de se desenhar uma pesquisa, apreender um determinado objeto e definir as técnicas que serão utilizadas para responder aos problemas que estão colocados. Pode-se sempre dizer que a pretensão não é a de refundar o campo, mas sim propor mudanças, críticas e alternativas possíveis a partir e dentro do que está posto. Em terceiro lugar, o gênero não precisa necessariamente ser tratado como uma categoria biológica porque supõe-se que pode ser apreendido por meio de dados. Uma saída poderia

15 Tickner (2006:19 n/r1) apresenta uma concepção bastante específica do que denomina "metodologia das ciências sociais". De acordo com a autora, são metodologias que estão comprometidas com a causalidade, teste de hipóteses e replicabilidade. O desafio a essa visão parte da ideia de acordo com a qual a complexidade do mundo social impossibilita que se espere o tipo de regularidade que poderia ser explicada por análises causais e ferramentas emprestadas das ciências naturais. E mais, a neutralidade dos fatos, suposta por estas metodologias, não poderia constituir fator necessário para a atribuição de verdade. 
ser, para ficar no caso que parece ser o mais complicado, a partir de definições socialmente construídas sobre o masculino e feminino, definir indicadores que expressariam essas construções para a composição de dados. Quarto, para enfatizar a posição defendida por Caprioli (2004, 2003, 2003a, 2000), a produção de dados sistematizados e a documentação de eventos e casos são resultados que não podem, de modo algum, ser diminuídos. No debate público nacional e internacional, na definição de políticas públicas, são estes dados e estas pesquisas que fundamentam boa parte das posições que pretendem lutar contra realidades de violência, dominação e opressão a que mulheres são submetidas.

\subsection{Ponto de vista feminista e as RI}

Diferente da percepção sobre o Estado defendida pelos feminismos empirista/racionalista, aqui este ator político é entendido como representante de um conjunto de práticas patriarcais que reproduzem e silenciam desvantagens estruturais às quais as mulheres estão submetidas. Já a concepção de gênero empregada, de modo geral, mantém uma dimensão corporificada do ser mulher. No entanto, este corpo não é apenas biológico: é um corpo constituído por entendimentos socialmente partilhados sobre o que é o feminino e o masculino. É importante lembrar que, para esta perspectiva, o que é socialmente construído como feminino e masculino é produto de uma certa história em um dado contexto, ou seja, são percepções que não podem ser generalizadas (HANSEN, 2010, p.21-22). Sendo assim, para esta perspectiva, masculinidade e feminilidade,

São empregadas para produzir e reproduzir a maneira adequada de ser homem e mulher (...). O ponto de vista feminista é cuidadoso em apontar que não se deve tomar a feminilidade e a masculinidade como construções uniformes que são idênticas no tempo e espaço ou presumir que as mulheres são inerentemente pacíficas e os homens violentos. Estudos têm apontado, por exemplo, mulheres como agentes de violência (Alison, 2004) ou para os papéis de gênero invertidos no escândalo de Abu Ghraib, particularmente o papel da - e a obsessão da mídia com a - guarda feminina Lynndie England (Enloe, 2004b). Crucialmente, no entanto, o ponto de vista feminista ainda mantém o entendimento de que existe um sujeito feminino concreto a quem pode-se fazer referência e que deve ser o centro da análise (HANSEN, 2010, p.22). 
Quando se mira, por sua vez, as técnicas de pesquisa - o método -, já deve ter ficado evidente que não há uma única alternativa. As análises contemplam desde apresentação de dados quantitativos, passam pelos estudos de caso que se aproximam das etnografias antropológicas e chegam até análises de narrativas. A decisão sobre o método, portanto, uma vez mais, não é aquilo que distingue essa perspectiva das outras.

E mais: o conjunto de preocupações e temas que norteiam esta abordagem tem foco distinto daquele adotado pelo feminismo empirista/racionalista. Para um feminismo que abraça o ponto de vista, as perguntas relevantes são: Que atora(e)s constituem o ponto de vista privilegiado para se analisar, explicar e interpretar as relações internacionais? Quem (ou qual grupo) ocupa essa perspectiva privilegiada? Qual o escopo de ação daquela(e)s que são considerada(o)s parte da perspectiva privilegiada? O que justifica o privilégio daquela(e)s que ocupam determinado lugar social? Que tipo de superioridade epistêmica é reivindicada por quem é considerado (e/ou se considera) o grupo privilegiado? Para respondê-las, mobilizam um repertório próprio, que procuraremos esboçar a seguir.

Até aqui, falou-se das ideias mais gerais de Estado, gênero e dos motivos que apoiam a afirmação de que pesquisas que se encaixam nesta perspectiva não podem ser definidas apenas pelas escolhas em relação ao método. No entanto, ainda não temos todos os traços que dão forma ao ponto de vista feminista. É crucial para que se examine a extensão destas ideias compreender a crítica radical elaborada pela teoria política feminista a respeito da distinção entre um domínio público e outro privado e de que modo esta crítica influencia a produção feminista nas RI.

A dicotomia entre razão e desejo é parte incontestável da teoria política moderna, afirma Iris Young, em seu texto $O$ ideal da imparcialidade e o público cívico. Esta divisão binária se reflete significativamente em outros domínios, sugere Young (2012), em especial no domínio universal e público da soberania e do Estado, por um lado, e no domínio particular e privado das necessidades, dos desejos e sentimentos, por outro. O privado refere-se, em termos gerais, a uma esfera ou 
esferas da vida social em que qualquer interferência em relação à liberdade requer justificativa especial, enquanto o público diz respeito a uma(s) esfera(s) geralmente ou justificadamente mais acessível(is) às regras do direito e da justiça, constituindo o espaço em que as narrativas sobre ter e reivindicar direitos ganham sentido (cf. OKIN, 2008) ${ }^{16}$.

Como a identificação desta distinção entre um âmbito público e outro privado está relacionada à produção do conhecimento? De um modo sutil, mas eficaz: determinadas identidades sociais e relações de poder podem ser fundamentais para o modo como concebemos, produzimos e qualificamos certos tipos de conhecimento sobre o mundo. Voltemos àquela distinção entre razão e desejo. Como lembra Alison Jaggar (1997, p.157), na tradição filosófica ocidental, as emoções têm sido consideradas como potencial ou realmente prejudiciais ao conhecimento. As mulheres, historicamente vinculadas ao lócus da família, do cuidado, das emoções e do desejo, foram consideradas menos preparadas para produzir conhecimento científico, o qual depende da razão - associada ao mental, ao cultural, ao universal, ao público e ao masculino -, e não da emoção, que é associada ao irracional, ao físico, ao natural, ao particular, ao privado e ao feminino.

Além de frequentemente fazerem estas denúncias sobre como tais dicotomias afetam o modo por meio do qual o conhecimento é produzido, feministas também chamam atenção para como o tipo de conhecimento, informação e verdade que as mulheres produzem constituem um ponto de vista incontornável para temas

\footnotetext{
${ }^{16} \mathrm{Na}$ passagem que segue, Young resume bem aquilo que se pode chamar, de modo geral, de crítica feminista à dicotomia público/privado. Nas palavras da autora: "Análises feministas recentes sobre a dicotomia entre público e privado na teoria política moderna sugerem que o ideal do público cívico como imparcial e universal é, em si, suspeito. Políticos e teóricos políticos modernos proclamaram a imparcialidade e a generalidade do público e, ao mesmo tempo, muito conscientemente consideraram adequado que algumas pessoas - mais especificamente mulheres, não brancos e, às vezes, os não proprietários - devessem ser excluídas da participação nesse público. Se não foi apenas um erro, isso sugere que o ideal do público cívico como expressão do interesse geral, do ponto de vista imparcial da razão, resulta, ele próprio, em exclusão. Ao pressupor que a razão se opõe ao desejo, à afetividade e ao corpo, essa concepção de público cívico exclui aspectos corporais e afetivos da existência humana. Na prática, essa suposição impõe a homogeneidade ao público cívico, excluindo do público aqueles indivíduos e grupos que não se encaixam no modelo do cidadão racional capaz de transcender corpo e sentimento. Essa exclusão tem base dupla: a tendência a opor razão e desejo e a associação dessas características a alguns tipos de pessoas". (YOUNG, 2012, p.185)
} 
caros às Rl: conflitos armados, guerra, paz, segurança, economia política internacional, política externa. Escutar essas vozes e seus contextos também pode significar a necessidade de romper com os limites tradicionais do campo. É o que ocorre quando o local e/ou a família passam a ser um locus de análise importante no momento em que o foco recai sobre fenômenos globais e internacionais.

Spike Peterson e Ann Runyan, em seu Global Gender Issues, nos ajudam a entender essa relação entre a crítica exposta até aqui e a produção de conhecimento nas RI. A política, afirmam a(s) autora(es)s, trata

do acesso diferenciado a recursos - tanto material quanto simbólico - e como tais relações de poder e estruturas são criadas, sustentadas e reconfiguradas. De acordo com uma definição mais ampla, a política opera em todos os níveis, variando da família e comunidade até o Estado e as esferas internacionais (PETERSON; RUNYAN, 1993, p.32).

Nesse sentido, o pessoal, o nacional e o internacional são - todos - domínios do político. Não pode haver uma linha de divisão intransponível entre esses níveis, o que significa, por exemplo, reconhecer que aquilo que é produzido e reproduzido domesticamente - e isso não significa apenas produção material: engloba também produção simbólica, de normas, de relações e de significados - pode ter implicações sobre o modo como a política externa é conduzida. Afirmação que posiciona Bananas, Beaches, and Bases [1989] como uma contribuição não só para as RI, mas também para a produção teórica feminista em um sentido mais amplo. Admitir que o ponto de vista das mulheres produz narrativas, histórias, verdades e conhecimentos relevantes para a compreensão, análise e para produção de respostas normativas é parte da mudança de foco proposta pela perspectiva feminista apresentada pelo ponto de vista feminista.

Retornar ao caso de Cyntia Enloe pode ser elucidativo. Partindo da percepção de que estereótipos de gênero - masculino e feminino - oferecem o enquadramento para a manutenção, operação e reprodução do sistema internacional, a autora mostra em seus trabalhos empíricos sobre a política internacional estadunidense de que modo as mulheres - exercendo diferentes papéis - conferem forma ao sistema internacional em alguns dos seus principais 
aspectos. Seriam as mulheres que proveriam os meios através dos quais a condução das relações internacionais oficiais seria conduzida: como escreve Enloe, mulheres

como amantes de empresários chineses, mulheres costurando roupas para Tommy Hilfiger e limpando pesticidas das bananas da Chiquita Bacana, mulheres casadas com agentes da CIA, mulheres trabalhando em boates ao redor das bases militares, mulheres se inscrevendo no concurso de Miss Universo, mulheres esfregando o chão na Arábia Saudita e mulheres fazendo campanhas de apoio a delegados nos corredores da ONU - elas observam, elas copiam, elas calculam, elas formulam estratégias e às vezes elas organizam. Aqui está o que eu aprendi ao levar estas mulheres a sério: se prestarmos contínua atenção a cada uma destas mulheres subestimadas, nós nos tornaremos mais inteligentes em relação ao mundo, mais espertos que muitos especialistas do mainstream (ENLOE, 1989, XIV).

Entender a dimensão da afirmação sobre "levar as mulheres a sério" significa menos olhar para a inexistência ou para os números que representam a quantidade de mulheres na arena internacional e mais para a maneira pela qual as construções sociais de gênero são parte importante daquilo que se convencionou chamar de política internacional. E mais, dessa conclusão é também possível depreender de que maneira dar atenção (teórica e analítica) para o ponto de vista das mulheres - ou de grupos sociais considerados oprimidos ou tradicionalmente invisíveis - pode resultar não apenas em respostas distintas para problemas tradicionais do campo, como também pode produzir questões novas anteriormente inomináveis.

Outra contribuição importante, e mais direta, da crítica feminista radical para os feminismos das $\mathrm{Rl}$ pode ser encontrada no campo da economia política internacional, especialmente naquelas abordagens que se identificam como neogramscianas. Começam a surgir questões sobre quais seriam os resultados de pesquisas que reconhecem a necessidade de a política econômica internacional incluir a contribuição das mulheres nos espaços domésticos de produção da vida material.

A problematização das consequências teóricas e políticas de se operar com as distinções tradicionais entre público e privado, do modo como foi descrito acima, 
abriu um leque de possibilidades para se questionar o modo como o trabalho doméstico realizado por mulheres estava sendo tratado até então. Para citar apenas um exemplo: dados sobre o produto interno bruto (PIB) não contemplam o trabalho doméstico, tornando invisível um grande número de trabalhadoras. É o que argumenta Anderson (1995) na seguinte passagem:

Nas nações avançadas industrialmente, economistas explicam esta omissão argumentando que os números do PIB medem corretamente somente o valor econômico da produção para o câmbio do mercado. Em nações em desenvolvimento, em que somente uma modesta parte da atividade de produção aparece no mercado de câmbio, economistas há tempos reconheceram a inutilidade de medidas de produção que olham somente para o mercado; por este motivo eles imputam um valor de mercado para várias atividades de produção domésticas que não são comercializáveis, associadas à agricultura de subsistência, construção de casas e coisas do tipo. Porém, qual destas atividades do lar os economistas escolhem contar como produtivas? Na prática eles definiram o 'limite de produção' em tais sociedades ao imporem conceitos de lar ocidentais, androcêntricos e obsoletos (ANDERSON, 1995, p.71-72).

Antes de passarmos aos limites que poderiam ser apontados sobre esta posição vale um alerta: tratar certo ponto de vista como o ponto de partida da produção de conhecimento não constitui uma inovação das teorias e/ou da epistemologia feminista. O modelo clássico da epistemologia do ponto de vista remonta ao materialismo histórico, tal como proposto por Karl Marx. Segundo a concepção de ideologia advogada pelo pensador social alemão, diferentes grupos sociais possuem pontos de vista epistêmicos distintos, sendo que o posicionamento material - fundamentalmente relacionado ao lugar ocupado por cada classe social no processo produtivo - de um grupo o coloca em um ponto de vista privilegiado em relação a outro grupo. O que o feminismo compartilha com o marxismo é esta ideia intuitiva de que, nas palavras de Miranda Fricker (2000, p.147), "uma vida inserida na dura realidade de quaisquer relações de poder fornece um entendimento crítico (do mundo social, em primeira instância) que não é percebido por aqueles(as) que levam uma vida amortecida pela posse do poder".

As críticas a esta perspectiva são muitas e variadas, de modo que a intenção aqui não é a de dar conta de toda a sua extensão. No entanto, como bem resumiu Anderson (2000), algumas posições ajudam a resumir um debate que é tão 
extenso quanto complicado. Helen Longino (1993b), por exemplo, argumenta que a perspectiva epistemológica do ponto de vista é incapaz de oferecer uma resposta não circular quando precisa justificar qual é o ponto de vista epistêmico privilegiado. Outra crítica importante é aquela que afirma que as mulheres não podem oferecer um ponto de vista privilegiado para o entendimento do seu próprio contexto de opressão, dado que esta realidade ganha formas distintas para diferentes mulheres dependendo da sua raça, orientação sexual, nacionalidade, e assim por diante. Isso quer dizer que não há um único ponto de vista feminino (ou da mulher) que possa ser considerado porta voz da expressão dos diferentes contextos de dominação e opressão aos quais todas as mulheres estão submetidas (LUGONES; SPELMAN, 1983; LAZREG,1994a, 1994b).

De modo bastante geral, sobre as críticas pode ser dito que, em primeiro lugar, o tipo de pesquisa que parte desta perspectiva epistêmica pode ser muito mais interseccional do que uma primeira aproximação parece supor. Não é necessário nem tampouco desejável afirmar a ideia de acordo com a qual o ponto de vista das mulheres abarcado por determinada pesquisa é universal e generalizável. Pelo contrário: é tanto possível quanto desejável que o lugar de fala seja tratado de modo contextualizado e situado.

Segundo, outro ponto importante é a ideia, pressuposta nesta visão, de que as pessoas são juízas qualificadas das próprias experiências. Concordar com tal afirmação não significa tomar as proposições de cada pessoa a respeito de si e das suas experiências como as únicas possíveis e/ou as últimas, mas sim defender que pontos de vista não podem ser sistematicamente suprimidos nem descartados, mesmo nos casos em que não se coloca em questão o valor moral da igualdade. É importante compreender que o foco do debate não é a disputa sobre a ideia de que toda(o)s são iguais: o centro do debate concentra-se, isto sim, na questão a respeito de como as pessoas são tratadas na produção e justificação do conhecimento.

Em terceiro lugar, esta perspectiva também pressupõe terem todas as pessoas o mesmo valor; e que isso deve ser parte das escolhas a serem feitas no momento em que uma pesquisa toma forma e conteúdo. Isso significa que poderá haver conflitos de interpretação sobre uma mesma situação; o grande desafio, 
portanto, é entender o poder de se falar a partir de um ponto de vista que foi (e em alguns casos continua a ser) calado. Nesse sentido, o desacordo é epistêmico e abre incontáveis possibilidades para a produção de um conhecimento que historicamente foi (e continua a ser) emudecido.

\subsection{Feminismo Pós-Moderno e as RI}

Que discurso de gênero é mobilizado pelos estados na construção da identidade nacional? Como as normas internacionais incidem nos corpos que antes estavam condenados ao privado e à natureza? Como surgem práticas de resistência à violência? A linguagem da violência pode ser produtiva? A tortura, por exemplo, se encerra na dor e no dano ou também cria/produz sujeitos particulares que podem ser torturados?

O conjunto de questões que são invocadas a partir de uma perspectiva pósmoderna, como se pode depreender, é bastante distinto das perguntas formuladas pelos feminismos tratados nas seções anteriores. Dado que tais interrogações são ao mesmo tempo variadas e complexas, torna-se tarefa especialmente complicada resumir, em forma de perguntas, o que pode ser entendido como representativo da perspectiva pós-moderna - dificuldade que se explica não apenas pela variedade de formulações internas ao movimento, mas especialmente pelo fato de que 0 movimento não pode ser resumido a uma ou outra área do conhecimento.

$\mathrm{Na}$ tentativa de enfrentar essa dificuldade, e para o exercício proposto neste artigo, o pós-modernismo será definido aqui como um movimento intelectual - para situar apenas o norte-americano - que tem como inspirações principais o pósestruturalismo e o pós-modernismo franceses, notadamente, os trabalhos de Michel Foucault, Jacques Lacan, Jacques Derida, Jean-François Lyotard e Luce Irigaray.

A ideia propulsora desta matriz intelectual é, segundo Anderson (2000, p. seção 3), a de que aquilo que pensamos e afirmamos ser a realidade é discursivamente construído. O foco das preocupações pós-modernas resume-se aos sistemas de pensamento e linguagem; o que não quer dizer que as práticas sociais não sejam igualmente relevantes: deve ficar mais evidente a seguir que, de modo 
geral, ações e práticas, por partilharem a mesma estrutura e dinâmica, também são tratadas como signos linguísticos.

O significado dos signos, entre os quais destacam-se as palavras, é resultado da sua relação com outros signos que, juntos, conformam certo sistema de discurso. Outro ponto importante: os signos e seus significados não são válidos em qualquer tempo ou lugar, além de serem necessariamente relacionais. Importa ainda lembrar que, se as mesmas ideias são válidas para ações e práticas, isso quer dizer que, assim como as palavras ganham significado na sua relação com outras palavras, a ação ganha significado na sua relação com outras ações, e não por causa de algum tipo de natureza humana pré-linguística ou em virtude de qualquer "lei natural". A mesma estrutura de explicação é aplicada às mudanças: os significados das ações são constantemente subvertidos por outras ações. E mais, alterar o contexto da ação acarreta mudança no e do significado da ação. Por isso, pós-modernos celebram ironias, paródias, transgressões de comportamentos, etc. como politicamente libertadores (cf. BUTLER, 1993). Todas essas ideias constituem e explicam a rejeição das chamadas meta-narrativas totalizantes.

Criticar a possibilidade de construir meta-narrativas sobre o mundo gera uma conclusão importante: a(o)s pós-moderna(o)s são céticos sobre a possibilidade de haver uma teoria completa que produza uma explicação totalizante/dora sobre 0 mundo e seus fenômenos. Teorias, explicações, conhecimento são apenas parciais; não podem ser completos e unificados. Aceitar esta afirmação implica subscrever a ideia de que a seleção de uma teoria ou narrativa particular é um exercício de poder - na medida em que exclui certas possibilidades, enquanto autoriza e legitima outras (ANDERSON, 2000). Daí a conclusão de acordo com a qual a atração crucial dos pós-modernos recai na sua capacidade de recolocar a razão e o conhecimento no contexto das relações de poder (FRICKER, 2007).

A partir dessa rápida definição, o que pode ser dito sobre a aplicação destas ideias para as RI? Não surpreende que o estado seja tratado, nessa perspectiva, com letra minúscula. O estado não é uma unidade ou entidade racional que pode ser destacado de seu contexto e tratado como único ator relevante, ou como um ator cujas ações são autorizadas por normas e regras consideradas legítimas, imparciais 
e/ou neutras. Isso quer dizer que é parte dos esforços empreendidos pela(o)s pósmoderna(o)s - que nas RI confundem-se com os estudos pós-estruturalistas compreender o estado como uma narrativa (linguagem) situada no tempo e no espaço, que se constitui e age em um contexto entrecortado por estruturas de poder que podem e devem ser desvendadas e desnaturalizadas. Quanto ao gênero, recusa-se a ideia segundo a qual as relações de poder e dominação, que marcam as relações gênero, serão desvendadas e combatidas na medida em que se explicita como as mulheres são marginalizadas. Tais autora(e)s acusam as teóricas do ponto de vista feminista de reforçarem uma noção naturalizada e biologizante de gênero e do sexo e enfatizam a urgência de se pensar o sentido performativo do gênero. Seguindo autoras como Judith Butler (2004), o gênero é definido nesta visão como uma atividade performativa incessante, como um tipo de fazer ("a kind of a doing") cuja prática é a do improviso. Os termos que fazem o gênero são, desde o início, sociais, ou seja, estão implicados em normas sociais e em relações e estruturas de poder.

Concordar com essas ideias exige que, para se tratar adequadamente ${ }^{17}$ das relações de gênero no campo das $\mathrm{RI}$, a solução identitária que os estados modernos tornaram prática corrente (Walker, 1992), aquela vinculada ao ideal da nação, seja revisada. Outra estratégia tem sido, como fizeram David Campbell (1992) e Roxanne Doty (1996), traçar os percursos de discursos generificados que são parte indissociável das narrativas sobre identidade nacional, segurança e desenvolvimento.

Para resumir o que foi dito até aqui, as análises feministas pósestruturalistas têm como foco desvendar o modo a partir do qual os discursos, inclusive aqueles que parecem opostos, constroem sujeitos, delimitam e legitimam cursos particulares de ações, de maneira que, como consequência, alguns objetos são silenciados por essa disposição dos discursos e das práticas (HANSEN, 2010, p.24). Lauren Wilcox (2015) propõe, um desenho de pesquisa que pode auxiliar na

\footnotetext{
${ }^{17}$ É importante ressaltar que tratar adequadamente significa também definir as técnicas de pesquisa que oferecem os meios mais adequados para responder aos problemas colocados, construir a análise proposta, e assim por diante. O mais usual é a aplicação de técnicas, tais como análise de discurso e de documentos, entrevistas e estudos de casos em profundidade.
} 
compreensão a respeito de como essas ideias, que em uma primeira aproximação podem parecer bastante abstratas, são mobilizadas em uma pesquisa.

As teorizações tradicionais das RI sofrem de um problema crônico, enfatiza Wilcox: são incapazes de tratar o corpo como um tema e/ou conceito relevante. Essa á uma síntese possível da crítica que a autora formula contra a tradição das RI, em geral, e aos estudos sobre segurança, em particular. Os corpos, sugere ela, seriam tratados pela tradição disciplinar como organismos individuais que devem ser mantidos seguros e protegidos. Nesse sentido, os corpos são apenas objetos da segurança. Como decorrência necessária, o foco dessas análises e explicações não pode recair sobre os corpos: são os estados ou grupos que fazem guerra e, ao fazêla, matam e violentam pessoas que deveriam ter sido protegidas por outros estados. A linguagem que domina essa visão é a da estratégia e do controle dos riscos; os sujeitos, quando aparecem, são completamente descorporificados. Como objetos dos estudos sobre segurança, as pessoas - protegidas, objetos da violência - são entendidas somente como corpos: corpos a-históricos, que sofrem, vivem e morrem; que são inertes, e existem para serem manipulados, possuídos (WILCOX, 2015, p.2).

O corpo como uma arma; o corpo que é alvo; o corpo que é atacado acidentalmente ou como efeito colateral; o corpo que é submetido à dor. Esses são os corpos que deveriam ser foco da atenção das pesquisas das RI preocupadas com os temas da soberania, da segurança, da violência e da vulnerabilidade ${ }^{18}$, sugere Wilcox. Esses corpos - que do ponto de vista da violência são apenas objetos - são entendidos como profundamente políticos, isto é, constituídos em contextos históricos e políticos ao mesmo tempo em que agem sobre o mundo no qual estão inseridos. Porque as teorias tradicionais são incapazes de captar essas outras dimensões dos corpos, argumenta Laura Wilcox (2015), falham em cumprir o

\footnotetext{
18 Os corpos de Bodies of Violence são aqueles que habitam Guantánamo, os corpos explosivos ("explosive bodies") das mulheres e homens bomba, os corpos que cruzam as fronteiras dos aeroportos e seus sistemas de segurança, os corpos que são objeto das armas de precisão ("precision warfare"), os corpos vulneráveis da responsabilidade de proteger (WILCOX, 2015).
} 
que deveria ser o objetivo primeiro da disciplina, qual seja: teorizar sobre a violência política internacional ${ }^{19}$.

Esta violência não pode ser entendida somente como um ato estratégico de atores racionais ou como violações destrutivas de leis e normas em uma certa comunidade. Justamente porque as RI convencionais concebem os corpos como não-políticos e irrelevantes para a subjetividade, elas se tornam incapazes de captar que a violência pode ser entendida como uma força criativa capaz tanto de (re)modelar percepções compartilhadas sobre como nos entendemos como sujeitos políticos quanto de criar e recriar as fronteiras dos nossos corpos e comunidades políticas. Nesse sentido, entender o que é a guerra passa por compreender como a guerra é uma força generativa única (BARKAWI; BRIGHTON, 2011, p.126; WILCOX, 2015, p.2)

As perspectivas feministas são a resposta mais acertada para o tipo de falha em que a literatura costuma incorrer, defende Wilcox, na medida em que permitem desnaturalizar categorias. E mais, tais miradas seriam capazes de analisar e expor as relações de força, violência e linguagem que constituem nossos corpos (que são também teóricos) profundamente não-naturalizados.

As críticas direcionadas a essa perspectiva também são variadas e têm origem em diferentes espectros teóricos. A mais relevante dentre elas para o pósestruturalismo feminista que se desenvolveu nas RI é, segundo Hansen (2010, p.24), a afirmação segundo a qual, ao desconstruir ideias estabelecidas (inclusive entre teorias feministas) acerca do gênero, esta abordagem termina por impossibilitar todo o projeto crítico feminista. Se as mulheres não são sujeitos que podem ser referenciados, como quer o ponto de vista feminista - porque são sujeitos essencialmente constituídos na e pela ação - como é possível falar sobre as desigualdades estruturais a que mulheres estão submetidas? Qual é o vocabulário alternativo àquele que transforma e explica a condição das mulheres como vítimas?

\footnotetext{
${ }^{19}$ Wilcox segue Butler e a relação que estabelece possível entre corpo e violência. De acordo com Butler: "O corpo implica mortalidade, vulnerabilidade, agência: a carne e o osso nos expõe ao olhar atento dos outros, mas também ao toque e a violência" (BUTLER, 2004a, p.26).
} 
Uma resposta possível a essa crítica é, primeiro, questionar a defesa da existência de um único projeto crítico feminista. Segundo, pode-se levantar a questão: e se o projeto for 0 de desconstruir categorias naturalizadas sem necessariamente propor qualquer nova unidade ou consenso sobre um novo sistema conceitual e analítico? Concordando-se ou não, outra saída, tem sido a de realçar a ideia de que as respostas sobre quais são os vocabulários a serem usados para expressar realidades de violência e dominação não são apenas respostas teóricas, no sentido de poderem ser formuladas de modo descolado da ação. Isso quer dizer que não há um único vocabulário possível: ele será sempre dependente dos e contestado pelos sujeitos em questão.

\section{Quão altas precisam ser as vozes para que possamos ouvi-las?}

As diferenças entre as perspectivas são muitas. Os objetos, as explicações e o tipo de conhecimento que é produzido por cada uma destas vertentes não necessariamente coincidem. Pesquisadora(e)s feministas tampouco partilham as mesmas orientações normativas, políticas e ideológicas (CARPENDER, 2003, p.299). E mais, p. o lugar que ocupam dentro do campo das RI também não é o mesmo - algumas posições são consideras internas ao campo, ou seja, contribuem ao oferecem respostas alternativas para os mesmos problemas já colocados pelas teorias tradicionais, enquanto outras pretendem expandir os limites da disciplina, questionando não apenas as explicações tradicionais, mas também o projeto mais amplo da produção de um conhecimento específico das RI.

Notar e considerar toda essa variedade, no entanto, não nos impede de afirmar que existe uma premissa partilhada pelas diferentes perspectivas apresentadas até aqui. Os feminismos e suas agendas de pesquisa partem da necessidade de se oferecer uma alternativa a um status quo em que as mulheres, suas histórias, seus lugares de fala, seus pontos de vista, mas também o modo como as relações de gênero são construídas e reproduzidas constituem um quadro composto por formas de exclusão sistemáticas da mulher e do feminino das atividades, do campo e da produção de conhecimento. 
Uma maneira de elaborar essa premissa, no sentido de entender o que ela engloba na crítica e no diagnóstico que produz, é a partir da ideia de silêncio. O que está sendo dito é que as teorias e práticas das Relações Internacionais - ao menos aquilo que constitui a tradição da disciplina - criam, reproduzem e reforçam o silenciamento de alguns grupos sociais, sendo que as mulheres constituem um desses grupos subalternos.

O silenciamento aqui é identificado com violência e injustiça. Isso significa não apenas que as mulheres, por exemplo, são forçadas ao silêncio ou que a elas não é garantido um espaço de fala. No sentido que está se discutindo aqui, a primeira conclusão que se pode chegar é a de que a manutenção de um campo que privilegia um certo tipo de discurso ou narrativa representa a manutenção de uma forma de violência e opressão epistêmica que precisa ser fortemente combatida.

As formas de injustiça geradoras de contextos de violência e opressão que se expressam através do silenciamento afetam a capacidade dos indivíduos de se constituírem como conhecedores - como portadores de algum tipo de conhecimento ou verdade. Dito de outro modo, quando pessoas estão sendo tratadas como se fossem incapazes de oferecer conhecimento ou informação, injustiças acontecem. Nesse sentido, existem dois tipos de injustiça epistêmica, p. uma é (a) testemunhal; a outra é (b) hermenêutica. Enquanto a primeira (a) significa, por exemplo, que um certo tipo de informação, conhecimento, narrativa e/ou história é falsa porque aquela que narra é uma mulher, a segunda injustiça (b) ocorre quando, por exemplo, a denúncia de uma mulher que sofreu violência sexual não é ouvida ou aceita porque nessa determinada comunidade linguística a violência sexual não é reconhecida como um conceito (FRICKER, 2007).

Quão alto mulheres precisam falar para serem ouvidas? O que mantém alguns grupos à margem da produção de conhecimento? Como essas escolhas afetam o conteúdo do conhecimento que produzimos? Protesta Enloe (1996, p.188). Uma vez mais, todas as respostas a essas questões levam-nos àquelas escolhas (mais ou menos conscientes) sobre como as agendas de pesquisa são formadas, o que é definido como importante para constituir o objeto de pesquisa, ou seja, de 
modo mais geral, qual tipo de conhecimento importa para o campo e como deve ser alcançado para que seja reconhecido (ouvido) como verdadeiro.

A esta altura, sabemos que as possibilidades de escolha em uma pesquisa são muitas. No entanto, juntas, as perspectivas feministas ora apresentadas fazem frente àquele tipo de injustiça e violência, chamada aqui de epistêmica. O seu maior potencial repousa justamente neste aspecto: podem ser entendidas como um esforço conjunto para formular respostas e saídas reais para investigações que se comprometem com um diagnóstico sobre a exclusão e o que ela produz e representa para aquelas e aqueles que estão na fronteira - seja da disciplina, da ação política ou da produção de conhecimento. Isso pode também significar que as epistemologias feministas carregam a potencialidade de abranger não somente questões relativas às mulheres e ao feminino: $E$ se os contextos de exclusão $e$ dominação forem formados por outros marcadores sociais e identitários, tais como raça, etnia, status e nacionalidade?

Questões como estas impõem um alerta importante. Ao se colocar em relevo, denunciar e/ou expor exclusões e formas de dominação e opressão de gênero, é preciso estar sempre alerta à possibilidade desse movimento produzir outros silêncios em relação a realidades e atores sociais que também experienciam contextos de violência que, contudo, não podem ser traduzidos pelas categorias de gênero ou sexo. O alerta é válido e importante; no entanto, de modo algum coloca em risco a contribuição das produções feministas para a epistemologia. Nesse sentido, as alternativas epistemológicas feministas não se encerram no gênero e nas pesquisas sobre as mulheres. Considerar o modo como a classe social, a raça e a etnicidade, entre outras formas de relações de poder, manifestam-se pode ser parte importante dos objetivos feministas (CHAN-TIBERGHIEN, 2004).

Por fim, especificamente em relação aos feminismos e as RI, a afirmação desdenhosa de que a entrada das mulheres e do gênero no campo das Relações Internacionais - e o tipo de teoria, pesquisa e resultados que passou a ser produzido - ainda é marginal na disciplina (TICKNER, 2001, p.3) ou ainda de que apresenta dificuldades em sua tentativa de transpor os obstáculos que surgem nessa busca de aceitação pelo mainstream da área (STEANS, 2003, p.448) não pode ser lida como 
sinal de fraqueza ou fracasso. A entrada dos feminismos nas $\mathrm{RI}$ proporcionou não apenas a incorporação de reflexões epistemológicas que vieram acompanhadas de desenhos de pesquisa e teorias (normativas e explicativas) alternativas (ACKERLY; STERN; TRUE, 2006), mas também chamou a atenção para a relação entre o modo como produzimos conhecimento e a possibilidade de se contribuir (ou não!) para o silenciamento de experiências, pontos de vista e lugares de fala diferentes daqueles dos cientistas que criam zonas de conforto analíticas e normativas que parecem tão seguras. Por todas essas razões, os feminismos são incômodos e talvez não possam ser inteiramente "aceitos" e/ou incorporados - o que não se aplica somente às RI. Talvez esse seja o preço a ser pago por perspectivas que, ao tentarem ouvir aquelas vozes reiteradamente caladas e olhar para os lugares negligenciados pelos vícios do status quo, pretendem suspender a validade daquilo que até então era produzido e reproduzido como verdadeiro e incontestável.

\section{Referências Bibliográficas}

ACKERLY, Brooke; STERN, Maria; TRUE, Jacqui (org.) Feminist Methodologies for International Relations. Cambridge: Cambridge University Press, 2006.

ALCOFF, Linda; POTTER, Elizabeth (org.) Feminist Epistemologies. New York: Routledge, 1993.

ANDERSON, Elizabeth. "Feminist epistemology: an interpretation and a defense". Hypatia, special issue: Analytic Feminist, v.10, n. 3, p. 50-84

- Feminist Epistemology and Philosophy of Science. In: ZALTA, Edward (org.). The Stanford Encyclopedia of Philosophy, 2000

BARKAWI, Tarak; Brighton, Shane. Powers of War: Fighting, Knowledge, and Critique. International Political Sociology, v 5, p. 126-143, 2011.

BASU, Amrita (org.) The Challenge of Local Feminisms: Women's Movements in Global Perspective. Boulder: Westview Press, 1995.

BORDO, Susan. The flight to objectivity: Essays on cartesianism and culture. Albany: State University of New York Press, 1987.

BROCK-UTNE, Birgit. Educating for Peace: A Feminist Perspective. New York: Pergammon Press, 1985.

BUTLER, Judith. Bodies that Matter. New York: Routledge, 1993.

. Undoing Gender. New York: Routledge, 2004.

. Precarious Life: The Power of Mourning and Violence. London and New 
York: Verso, 2004a.

CAMPBELL, David. Writing Security: United States Foreign Policy and the Politics of Identity. Minneapolis: University of Minnesota Press, 2000 [1992].

CAPRIOLI, Mary. Gendered Conflict. Journal of Peace Research, v. 37, n. 1,p. 5168, 2000.

Feminist Phallacies or Scientific Certainties? Examining Feminist Criticisms of Feminist Empiricists and of 'Mainstream' IR. Paper apresentado no The annual meeting of the International Studies Association, Portland, 26 de fevereiro - 1 de março, 2003.

.Gender equality and state aggression: the impact of domestic gender equality on state first use of force. International Interactions, v. 29, n. 3, p.195-214, 2003a.

. Feminist IR Theory and Quantitative Methodology. International Studies Review, v. 6, n. 2,p. 253-269, 2004.

CAPRIOLI, Mary. BOYER, Mark. Gender, Violence, and International Crisis. Journal of Conflict Resolution, v. 45, n. 4,p. 503-518, 2001.

CARPENTER, R. Charli. Stirring Gender into the Mainstream: Feminism, Constructivism and the Uses of Theory." International Studies Review, v. 5, n. 2,p. 287-300, 2003.

CHAN-TIBERGHIEN, Jennifer. Gender-skepticism or Gender Boom? Poststructural Feminisms, Transnational Feminisms, and the World Conference Against Racism. International Feminist Journal of Politics, v. 6, n. 3,p. 454-484, 2004.

COADY, Cecil. Testimony: a philosophical study. Oxford, New York: Clarendon Press; Oxford University, 1992.

CODE, Lorraine. Rhetorical spaces: Essays on gendered locations. New York; Routledge, 1995.

COLLINS, Patricia Hill. Black feminist thought: knowledge, consciousness, and the politics of empowerment. New York: Harper, 1990.

COOK, Judith; FONOW, Mary. Knowledge and Women's Interests: Issues of Epistemology and Methodology. Feminist Sociological Research.Sociological Inquiry, 56, 1, p. 2-29. Reimpresso In: NIELSEN, Joyce. Feminist Research Methods. Boulder: Westview Press, p. 69-93, 1990.

DAUKAS, Nancy. Altogether Now: A Virtue-Theoretic Approach to Pluralism in Feminist Epistemology. In: GRASSWICK, Heidi. Feminist Epistemology and Philosophy of Science. London, New York: Springer Science, 2011.

DIETZ, Mary. Citizenship with a Feminist Face: The Problem with Maternal Thinking. Political Theory, v. 13, n. 1, p. 19-38, 1985.

DEVAULT, Marjorie. Liberating Method: Feminism and Social Research. Philadelphia: Temple University Press, 1999. 
DOTY, Roxanne. Imperial Encounters: The Politics of Representation in North-South Relations. Minneapolis: University of Minnesota Press, 1996.

DURAN, Jane. Toward a feminist epistemology. Totowa, NJ: Rowman and Littlefield, 1991.

EICHENBERG, Richard. Gender Differences in Attitudes Toward the Use of Force by the United States, 1990-2003. International Security, v. 28, n. 1,p. 110-141, 2003.

ENLOE, Cynthia. (1989) Bananas, Beaches, and Bases: Making Feminist Sense of International Relations. London: Pandora Press.

Margins, silences and bottom rungs: how to overcome the underestimation of power in the sutdy of international relations. In: SMITH,Steve; BOOTH, Ken; ZALEWSKI, Marysia. International Theory: Positivism and Beyond. Cambridge: Cambridge University Press, p. 186-202, 1996.

FRICKER, Miranda. Pluralism Without Postmodernism In: Fricker, Miranda; Hornsby, Jennifer. (org.) The Cambridge Companion to Feminism in Philosophy. Cambridge: Cambridge University Press, p. 146-165, 2000.

Epistemic Injustice: Power and the Ethics of Knowing. Oxford: Oxford University Press, 2007.

GATENS, Moira. Modern Rationalism. In: JAGGAR, Alison; YOUNG, Iris. (org.) A Companion to Feminist Philosophy. New York: Wiley-Blackwell, 2000.

GLUCK, Sherna. PATAI, Daphne. (org.) Women's Words: The Feminist Practice of Oral History. New York: Routledge, 1991.

GRASSWICK, Heidi. Feminist Epistemology and Philosophy of Science. London;New York: Springer Science, 2011.

HANSEN, Laura. Ontologies, Epistemologies, methodologies. In: SHEPHERD, Laura. (org.) Gender Matters in Global Politics: A feminist introduction to International Relations. London;New York: Routledge, p. 14-23, 2010.

HARAWAY, Donna. Situated Knowledges: The Science Question in Feminism and the Privilege of Partial Perspectives. Feminist Studies, v. 14, n. 3, p. 575-599, 1988.

HARDING, Sandra. The Science Question in Feminism. Ithaca: Cornell University Press, 1986.

Introduction: is There a Feminist Method? In: HARDING, Sandra. Feminism and Methodology: Social Science Issues. Milton Keynes: Open University Press, p. 1-14, 1987.

Whose Science? Whose Knowledge? Thinking From Women's Lives. Ithaca: Cornell University Press, 1991.

Is Science Multicultural? Postcolonialism, Feminisms, and Epistemologies. Bloomington: Indiana University Press, 1998. 
HÖFFE, Otfried. Kants Kritik der reinen Vernunft. Die Grundlegung der modernen Philosophie. München: Verlag C.H. Beck, 2003.

INTEMANN, Kristen. "25 Years of Feminist Empiricism and Standpoint Theory: Where Are We Now?" Hypatia: A Journal of Feminist Philosophy, v. 25, n. 4, p. 778796, 2010.

JAGGAR, Alison. Feminist Politics and Human Nature. Totowa, NJ: Rowan \& Allenheld, 1983.

. Amor e conhecimento: a emoção na epistemologia feminista .In: JAGGAR, Alison; BORDO, Susan (org). Gênero, Corpo, Conhecimento. Rio de Janeiro: Record: Rosa dos Ventos, p. 157-185, 1997.

JONES, Adam. Does 'Gender' Make the World go Round? Feminist Critiques of International Relations". Review of International Studies, v. 22, n. 4, p. 405-429, 1996.

KEOHANE, Robert. "International Relations Theory: Contributions of a Feminist Standpoint". Millennium - Journal of International Studies, v. 18, n. 2, p. 245-253, 1989.

KINSELLA, Hellen. For a Careful Reading: The Conservativism of Gender Constructivism. International Studies Review, v. 5, n. 2, p. 294-297, 2003.

KLEIN, Renate. How to Do What We Want to Do: Thoughts about Feminist Methodology. In: BOWLES, Gloria; KLEIN, Renate (org.) Theories of Women's Studies. London: Routledge and Kegan Paul, p.88-104, 1983.

LAZREG, Marnia. Women`s Experience and feminist epistemology. In: Lennon, K. Whitford, M. Knowing the Difference. New York: Routledge, 1994a.

Routledge.

(1994b) The Eloquence of Silence: Algerian Women in Question. London:

LLOYD, Elisabeth. Objectivity and the Double Standard for Feminist Epistemologies. Synthèse, 104, p. 351-81, 1995.

LONGINO. Helen. Science as social knowledge. Princeton, NJ: Princeton University Press, 1990.

Essential tensions-Phase two: Feminist, philosophical, and social studies of science. In: ANTONY, Louise; WITT, Charlotte (org.) A mind of one's own: Feminist essays on reason and objectivity. Boulder: Westview, p. 257-272, 1993a.

Subjects, power, and knowledge: Description and prescription in feminist philosophies of science. In: ALCOFF, Linda; POTTER, Elizabeth (org.) Feminist epistemologies. New York: Routledge, p. 101-120 1993b. . In Search of Feminist Epistemology. The Monist, v. 4, p.472-485, 1994.

LUGONES, Maria. SPELMAN, Elizabeth. Have we got a theory for you! Feminist theory, cultural imperialism and the demand for 'the woman's voice". Women's Studies International Forum, v. 6, n. 6, p. 573-581, 1983. 
MACKINNON, Catharine. Feminism Inmodified: Discourses on Life and Law. Cambridge; MA; London: Harvard University Press, 1987.

MAYNARD, Mary. PURVIS, June. Researching Women's Lives from a Feminist Perspective. London: Taylor and Francis, 1994.

MELANDER, Erik. Gender equality and intrastate armed conflict. International Studies Quarterly, v. 49, p. 695-714, 2005.

NELSON, Lynn. Who knows? From Quine to a feminist empiricism. Philadelphia: Temple University Press., 1990.

NIELSEN, Joyce (org.) Feminist Research Methods: Exemplary Readings in the Social Sciences. Boulder: Westview Press, 1990.

OKIN, Susan. Gênero, o público e o privado. Estudos Feministas, Florianópolis, v. 16, n. 2, p. 305-332, p. 2008.

PETERSON, Spike (org.) Gendered States: Feminist (Re)Visions of International Relations Theory. Boulder: Lynne Rienner Press, 1992.

PETERSON, Spike. Runyan, Anne.Global Gender Issues. Boulder, Colo; San Francisco; Oxford: Westview Press, 1993.

REGAN, Patrick; PASKEVICIUTE, Aida. Women's access to politics and peaceful states. Journal of Peace Research, v. 40, n. 3, p. 287-302, 2003.

REINHARZ, Shulamit. Feminist Methods in Social Research. New York: Oxford University Press, 1992.

RUIZ, Tricia. Feminist Theory and International Relations: The Feminist Challenge to Realism and Liberalism. Soundings Journal, s/p, 2005.

SMITH, Dorothy. Writing the Social: Critique, Theory, and Investigations. Toronto: University of Toronto Press, 1999.

SMITH, Linda. Decolonizing Methodologies: Research and Indigenous Peoples. London: Zed Books, 1999.

STEANS, Jill. Engaging From the Margins: Feminist Encounters with the "Mainstream" of International Relations". British Journal of Politics and International Relations, v. 5, p. 428-454, 2003.

SYLVESTER, Christine. Feminist Theory and International Relations in a Postmodern Era. Cambridge: Cambridge University Press, 1994.

Feminist International Relations: An Unfinished Journey. New York: Cambridge University Press, 2004.

TICKNER, J. Ann. Gendering World Politics: Issues and Approaches in the PostCold War Era. New York: Columbia University Press, 2001.

Feminism meets International Relations: some methodological issues. In: ACKERLY, Brooke; STERN, Maria; TRUE, Jacqui (org.) Feminist Methodologies for International Relations. Ackerly, Cambridge: Cambridge University Press, p. 19-41, 2006. 
TICKNER, Ann; SJOBERG, Laura (org.) Feminism and International Relations: Conversations about the past, present and future, 2011.

TOGEBY, Lise. The gender-gap in foreign policy attitudes. Journal of Peace Research, v. 31, n. 4, 375-392, 1994.

YOUNG, Iris. O ideal da imparcialidade e o público cívico. Rev. Bras. Ciênc. Polít. n.9, p. 169-203, 2012. Disponível em: $<$ http://www.scielo.br/scielo.php?script=sci_arttext\&pid=S010333522012000300007\&lng=en\&nrm=iso.$\quad$ ISSN 0103-3352. http://dx.doi.org/10.1590/S0103-33522012000300007. Acessado em 10 de fevereiro de 2017.

WALKER, Rob. Gender and Critique in the Theory of International Relations. In: Peterson, V. Spike. (org.) Gendered States: Feminist (Re)Visions of International Relations Theory. Boulder, CO: Lynne Rienner, p. 179-201, 1992.

WEBER, Cynthia. Good Girls, Little Girls, and Bad Girls: Male Paranoia in Robert Keohane's Critique of Feminist International Relations". Millennium - Journal of International Studies, v. 23, n. 2, p. 337-349, 1994.

Routledge, 2010.

WELDON, Laurel. Inclusion and understanding: a collective methodology for feminist International Relations. In: ACKERLY, Brooke. STERN, Maria. TRUE, Jacqui. Feminist Methodologies for International Relations. Cambridge: Cambridge: University Press, p. 62-87, 2006.

WILCOX, Lauren. Bodies of Violence: Theorizing Embodied Subjects in International Relations. Oxford: Oxford University Press, 2015. 